\title{
Franchise Revenue Guarantee Valuation: Real Options Approach
}

\author{
Lukito Adi Nugroho \\ Graduate School of Advanced Mathematical Sciences, Meiji University, Tokyo, Japan \\ Email: lukito@meiji.ac.jp
}

Received 13 November 2014; accepted 2 March 2015; published 5 March 2015

Copyright (C 2015 by author and Scientific Research Publishing Inc.

This work is licensed under the Creative Commons Attribution International License (CC BY). http://creativecommons.org/licenses/by/4.0/

(c) (i) Open Access

\begin{abstract}
In order to survive in the current severe competition, newly established franchises have been looking for new ways to encourage more individuals to become their franchisees. One approach that becoming increasingly widespread is the inclusion of revenue guarantee. This feature attracts risk averse franchisees because it reduces the apparent risk of joining a franchise with the reassurance that they will earn predetermined level amount of income at the early period of the franchise operation. This paper develops analytical framework using real options approach to value revenue guarantee in business format franchise. The model also will be tested using Monte Carlo simulation to assess the impact of the revenue guarantee agreements on franchisee's present value. Result shows that guarantee is more needed in higher uncertainty environment, but it also comes with a higher cost.
\end{abstract}

\section{Keywords}

Real Options, Franchise, Financial Contract, Monte Carlo Simulation

\section{Introduction}

Even though franchise has grown rapidly in the last few decades, the impression that franchise is a safer road to entrepreneurship is sometimes misleading. Despite all the franchise contribution as a form of organization which people usually perceived, franchise has some lower survival rate compare to independent business (Bates, 1995) and growth of franchise as a business is not as fancy as it seems (Blair \& Lafontaine, 2005).

This fact drives competition among franchise businesses, especially the newly established one. These franchises have to come up with new ideas to attract its potential franchisee. One method that proven successful is the attachment of revenue guarantee. The revenue guarantee is the promise of payment in the future by the franchisor to the franchisee if the business could not perform as projected. The amount of this payment is set by 
mutual consent of both parties. The main objective behind making such payments is to convey franchisor confidence that the franchise will run as they promised.

When a franchisee previously accustomed to a fixed wage routine opts to get into franchising business, he/she might be alarmed of the irregularities of self-employment. To help franchisee overcome this fear, a revenue guarantee provides relief to the franchisees for their living costs. In this way, revenue guarantees serve as an incentive for the franchisees. The franchise revenue guarantee purpose is also to provide working capital to the beginning of operation, which helps the franchisee to keep its business operational until it starts giving profits.

The major drawback of revenue guarantees is that it increases the original cost of the franchise. As the franchisor will need extra cost to provide guarantee in order to anticipate the future payments, franchisor have to pay if the franchise under perform.

This paper's objective is to provide an analytical framework for franchise revenue guarantee. The valuation framework quantitatively measured the value of joining revenue guarantee program and then derived the joining fee of revenue guarantee program using real options approach.

This paper is organized as follows: Section 2 is a literature review which summarizes relevant research about franchising and real options, while in Section 3, the conceptual framework of this paper is explained and the model will be introduced. All the models tested using Monte Carlo simulation to analyze the model dynamic in Section 4. In Section 5, we derive the options pricing in order to get the FRG fee. In Section 6, the decision framework for the franchisee to join guarantee program will be discussed and Section 7 concludes.

\section{Literature Review}

This paper is an intersection of the real options analysis and franchise literatures. Even though there is a large body of literature discussing franchising financial contract, most of them using empirical model. This study is one of the few which uses theoretical model, specifically real options analysis to analyze franchise contract.

Real options approach for valuing guarantee also used in BOT (Build Operates Transfer) research where Wibowo (2011) comparing several guarantee model in the case of Indonesia toll road. In addition, Chiara et al. (2007) focusing on multiple exercise using Bermudan and Australian options, while Jun (2010) combine the guarantee with revenue cap agreement. The closest study to our current paper is Lee (2010), where he construct dynamic model in order to derive the value of franchise and timing to invest on franchise contract using real options approach.

The paper main differences with those previous model is while most of the real options model uses either Brownian Motion or binomial process for underlying stochastic path, we are going to use the log-DD model introduced by Kariya and Liu (2002). This model feature a discrete time and path-dependent process, a more realistic approach for non-financial derivative valuation.

\section{Model Specification}

\subsection{General Assumption}

We focus on relationship between franchisor and franchisee in business format franchise. The franchise is a newly established business that wants to attract as many potential franchisees as possible. Furthermore, potential franchisees has alternatives investment, which mean they could consider another investment other than what franchisor offer. The current and future value of the franchise we assume to be stochastic as franchise competitive strength will drive the revenue of the franchise itself.

In order to appeal potential franchisee, franchisor offers Franchise Revenue Guarantee (henceforth we called $F R G$ ) program, an extra protection for minimum revenue. If they choose to invest in franchise business, the franchisee can choose to join the $F R G$ program or not. Franchisee know that $F R G$ will comes with extra fee that should be paid in the beginning of the contract. This fee, from now on we address as FRG fee.

We consider $T$ years as one contract period before franchise asked to renew the contract. Usually, there would be an initial franchise fee that franchisor charges on the beginning of the contract and recurring royalty fee as percentage of the revenue, but without loss of generality, we assume to be zero.

The amount of guarantee, $K$ will be represented as ratio of Revenue at time $0\left(S_{0}\right)$. For the guarantee period, will be represented by $N$ years, which will be set by franchisor and cannot be negotiated. We will relax these assumptions on the Section 6 to give more insight on the franchisee decision framework in decision in joining FRG. 


\subsection{Franchisee Payoff}

We are going to use Discounted Cash Flow (DCF) procedure to measure franchisee's Present Value $(P V)$ as a proxy of franchisee payoff during the period of franchising. Being able to measure the $P V$ of an investment's cash flows becomes useful for potential franchisee to compare franchise investment to other alternatives as value of all the investments can be measured at some common point in present time.

$P V$ is calculated by projecting cash flow onward and discounted back to present time using suitable discount rate $(d)$. At the period of guarantee, franchisee cash flow would be either revenue at current period, $S n$ or guaranteed amount, $K$, which one is higher. After the guarantee period is over, cash flow only from $\mathrm{Sn}$;

$$
P V=\sum_{n=1}^{N} \frac{\max \left(K, S_{n}\right)}{(1+d)^{n}}+\sum_{n=N+1}^{T} \frac{S n}{(1+d)^{n}}
$$

\subsection{Underlying Asset Path}

When using stochastic model, the most important aspect is the revelation of information over time. Typically multi-period models are divided into two categories:

1) Continuous Time: where time is taken as an infinite quantity, denoted by the interval [0:T];

2) Discrete Time: where time is taken as a finite set of dates, denoted by $[0,1, \cdots, T]$.

In the case of real asset, like in this paper, it will be more appropriate if we use discrete model as the stochastic object is revenue, which accrue discretely. We assume that the revenue process in this paper follows logdiscrete time diffusion model (Kariya \& Liu, 2002);

$$
S_{n}=S_{n-1} \exp \left[\mu_{n-1}+\sigma \varepsilon_{n}\right]
$$

where $\mu_{n-1}$ is the drift function and $\sigma$ is the diffusion process. $\mu_{n-1}$ and $\sigma$ are time varying factor depend on $S_{n-1}=\left(S_{n-1}, S_{n-2}, \cdots, S_{1}, S_{0}\right)$. While for the drift, $\mu_{n-1}$ is using exponential smoothing model as described below;

$$
\mu_{n-1}=\varnothing \ln \frac{S_{n-1}}{S_{n-2}}+(1-\varnothing)
$$

The smoothing parameter $\varnothing$ indicates the level of diffusion on the revenue growth, $\ln \frac{S_{n-1}}{S_{n-2}}$ to the revenue stochastic process. Bigger smoothing parameter means that yearly changes are quickly incorporated to the trend movement. Similar model also used in Kariya et al. (2005) in valuing lease agreement in commercial real estate in Japan. Figure 1 shows sample paths of the revenue stochastic process that generated from Equations (2) and (3).

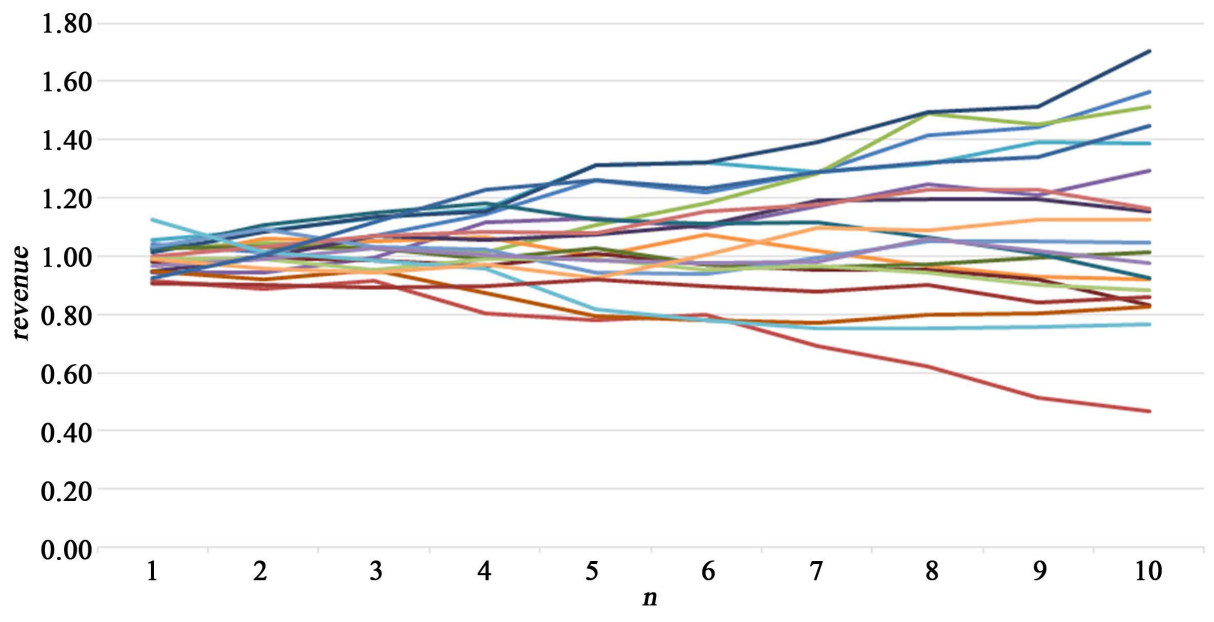

Figure 1. Twenty sample paths generated using Equations (2) and (3). 


\section{Sensitivity Analysis}

In order to know the impact of variable to the model, we conduct sensitivity analysis to $\sigma$, $\varnothing$ and $\mu_{0}$, which represent volatility, smoothing parameter and the initial drift respectively. For this study, we are using Oracle Crystal Ball ${ }^{\mathrm{TM}}$ as the Monte Carlo simulator.

This section will be divided into two sub-sections to describe in detail how these variables impacted the $P V$ distribution. Sub-Section 4.1 focusing on how variables impacted the $P V$ distributions without FRG, while the sub-Section 4.2 focusing on PV distributions with FRG.

For the base case, we use these following variables:

$$
\varnothing=0.4, \sigma=4 \%, \mu_{0}=0 \%, S_{0}=1 \mathrm{mu}(\text { monetary unit), } d=5 \%
$$

While in the case of FRG, we use the base case for guaranteed amount, $K=1 S_{0}$ and three years guaranteed period, $N=3$.

In the Subsection 4.1 we measure the $P V$ distribution using these statistical measurement; mean, lower semi deviation $(L S D)$, skewness and kurtosis. While most of the measurements are the standard statistical procedure, we would like to introduce the lower semi deviation $(L S D)$ as a risk measurement of $P V$ falls below the mean. LSD computed as follows;

$$
\text { lower semi deviation }(L S D)=\sqrt{\sum_{i=1}^{M} \frac{\left\{\min \left(P V_{i}-\overline{P V}, 0\right)\right\}^{2}}{M}}
$$

where $M$ is number of trial, $P V_{i}$ is the value of $P V$ on the $i$-th trial, and $\overline{P V}$ is the mean. In other words, in the $L S D$, risk is considered the downside part below the mean in each trial. In this definition a smaller lower semi deviation guarantees a smaller possibility that the values fall below mean.

In the Subsection 4.2, we also measure the return and risk improvement when franchisee decides to join FRG. The measurement for valuing improvement as a result of joining FRG is calculated as following:

and

$$
r M E A N=\frac{\text { mean }_{F R G}-\text { mean }_{n F R G}}{\text { mean }_{n F R G}}
$$

$$
r L S D=\frac{L S D_{F R G}-L S D_{n F R G}}{L S D_{n F R G}}
$$

where $r M E A N$ is a measurement of return improvement and $r L S D$ is a measure of risk improvement over the non-FRG program. The suffice FRG and $n F R G$ represent with or without FRG respectively.

For the return to risk improvement, it can be measured by mean to LSD ratio of FRG case reduced by mean to $L S D$ ratio of non-FRG case;

$$
\text { RRimp }=\frac{\text { mean }_{F R G}}{L S D_{F R G}}-\frac{\text { mean }_{n F R G}}{L S D_{n F R G}}
$$

where RRimp is a return to risk improvement. So if RRimp is positive, it justifies franchisee to join FRG because mean to $L S D$ ratio is improved.

\subsection{The PV Distribution for Non-FRG Program}

First, we observe how the volatility $(\sigma)$ impacted $P V$ distribution. The variable to be tested is ranging from $2 \%$, $4 \%, 6 \%, 8 \%$ to $10 \%$.

Table 1 listed all the statistical values on every volatility variations, while Figure 2 is a graphical representation of Table 1 . From the Table 1 and Figure 2 we can observe the following:

- In general, as the $\sigma$ increase, we can see the mean also increasing along with risk measurement (LSD). This is a logical consequence as $\sigma$ is a measure of volatility on the revenue stochastic model, which leads to typical high risk-high return case.

- The skewness and kurtosis increases as $\sigma$ increase. As we can see in the Figure 2, when volatility is low, the $P V$ distribution is closest to normal distribution. However at the highest volatility tested, $\sigma=10 \%$, the distribution is reached highest peak and immensely skewed to the right. 


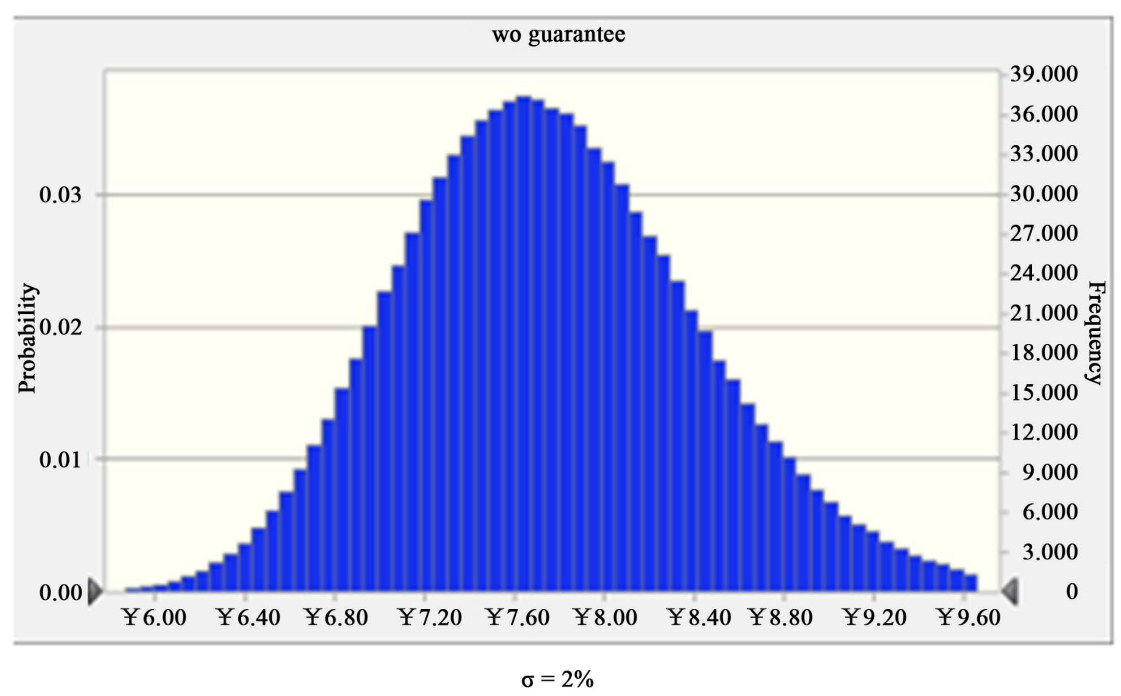

(a)

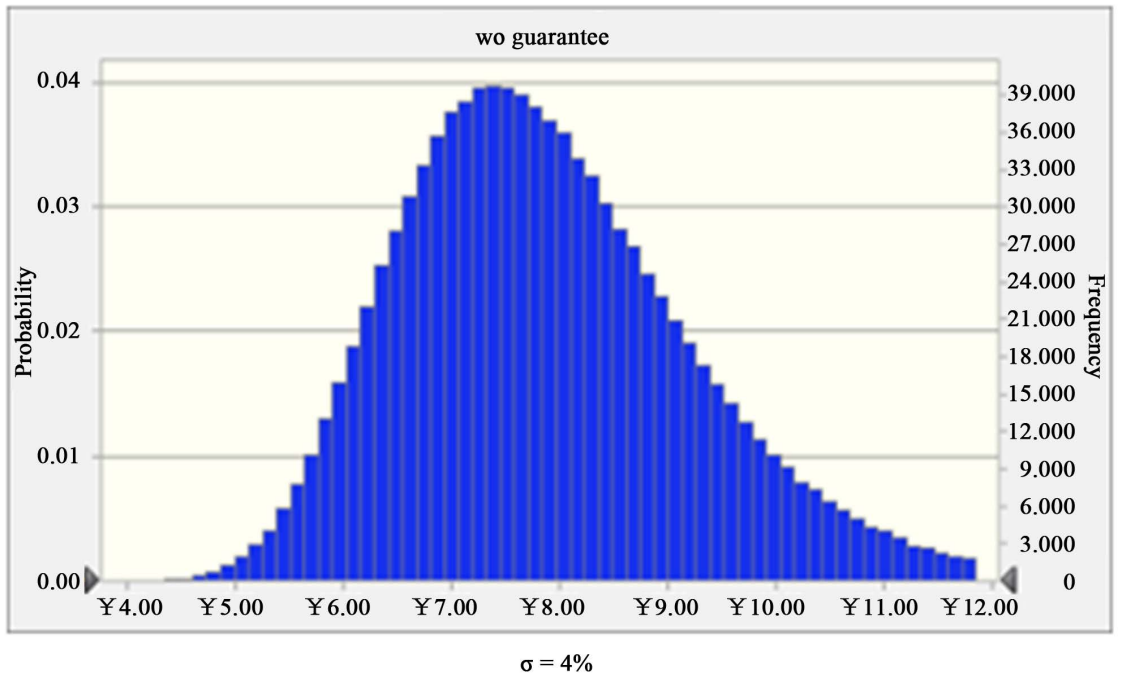

(b)

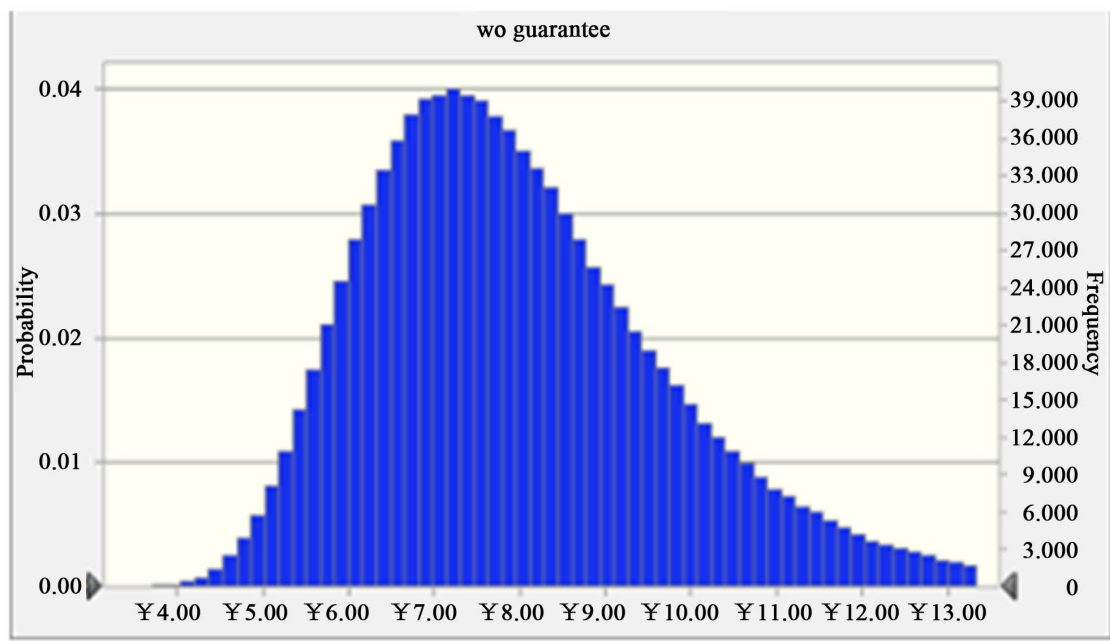

$\sigma=6 \%$

(c) 


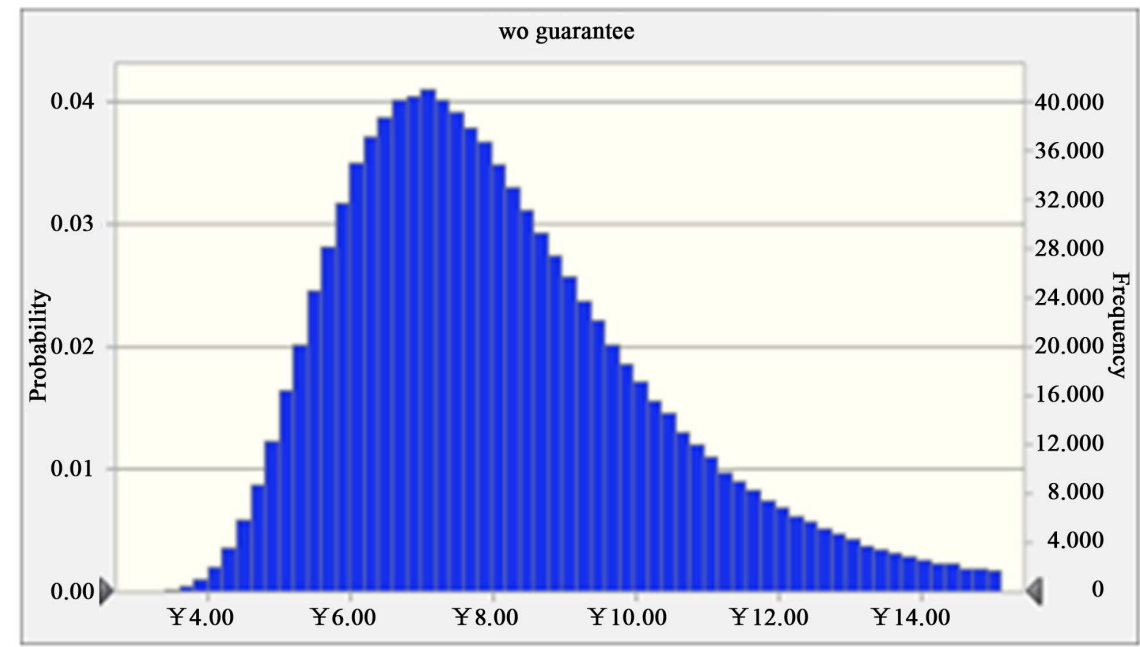

(d)

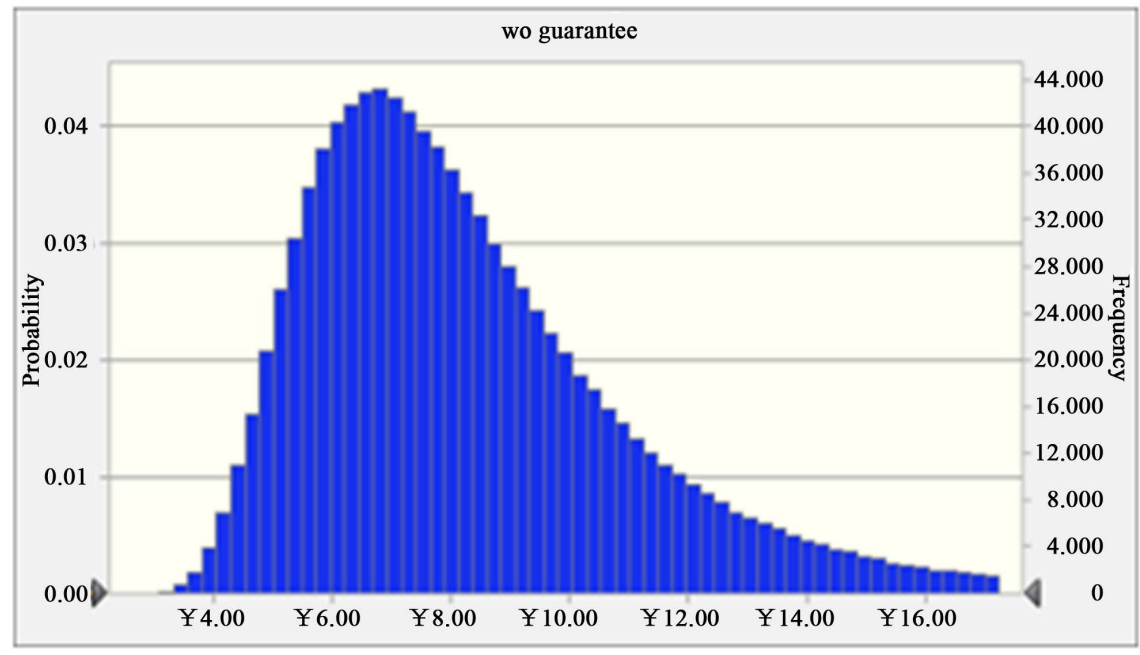

(e)

Figure 2. Illustration of $P V$ values on $\sigma$ variations.

Table 1. $P V$ values on $\sigma$ variation.

\begin{tabular}{|c|c|c|c|c|c|}
\hline \multirow{2}{*}{$\sigma$} & \multicolumn{5}{|c|}{ Statistics } \\
\hline & Mean & $L S D$ & Skewness & Kurtosis & Range width \\
\hline $2 \%$ & 7.765 & 0.455 & 0.369 & 3.258 & 6.722 \\
\hline $4 \%$ & 7.899 & 0.893 & 0.779 & 4.149 & 15.212 \\
\hline $6 \%$ & 8.132 & 1.342 & 1.265 & 6.257 & 42.573 \\
\hline $8 \%$ & 8.479 & 1.827 & 1.890 & 10.453 & 69.837 \\
\hline $10 \%$ & 8.981 & 2.388 & 2.839 & 21.583 & 161.148 \\
\hline
\end{tabular}

- The most obvious direct consequences of increasing volatility is the data range width. At $\sigma=2 \%$, the $P V$ range 6.72 from its minimum to maximum, while at the highest volatility $(\sigma=10 \%)$, the range width increase substantially to 161.48 .

The second part for this sub-section is to observe the $P V$ distribution dependency to smoothing parameter. As seen on the Table 2, most of the statistical value have the same tendencies to our previous data on volatility 
Table 2. $P V$ values on $\varnothing$ variation.

\begin{tabular}{|c|c|c|c|c|c|}
\hline \multirow{2}{*}{$\varnothing$} & \multicolumn{5}{|c|}{ Statistics } \\
\hline & Mean & $L S D$ & Skewness & Kurtosis & Range width \\
\hline 0 & 7.753 & 0.395 & 0.260 & 3.128 & 5.865 \\
\hline 0.2 & 7.807 & 0.644 & 0.499 & 3.466 & 11.459 \\
\hline 0.4 & 7.899 & 0.893 & 0.779 & 4.149 & 15.212 \\
\hline 0.6 & 8.030 & 1.149 & 1.096 & 5.346 & 26.357 \\
\hline 0.8 & 8.209 & 1.419 & 1.499 & 7.607 & 44.857 \\
\hline 1 & 8.444 & 1.710 & 1.989 & 11.312 & 59.823 \\
\hline
\end{tabular}

variations. However, at the highest variation tested $(\varnothing=1)$ compare to the lowest variation $(\varnothing=0)$, the difference is less significant compare to volatility variations. The fact that smoothing parameter represent the new information on revenue changes and reflected to the next period level, a higher $\varnothing$ will cause the revenue changes more rapidly into the market trend movement. Figure 3 illustrate the $P V$ distributions from $\varnothing$ variations.

The last part in this sub-section is to observe the changes of $P V$ distributions on the initial drift $\left(\mu_{0}\right)$ variation (Table 3). Similar to other previous observation, mean, $L S D$, skewness and kurtosis are all increase as $\mu_{0}$ increase from $-4 \%$ to $4 \%$. As $\mu$ represent drift rate (average rate of change in the revenue stochastic process), positive $\mu_{0}$ makes the revenue stochastic process tend to move higher. Therefore the $P V$ values is higher when $\mu_{0}$ is positive. Figure 4 illustrate the PV distributions from $\mu_{0}$ variations.

\subsection{The $P V$ Distribution for $F R G$ Program}

For the next observation, we want to compare the $P V$ distribution of FRG program against non-FRG program. We also want to measure the return improvement and risk improvement on joining FRG program. The variables to be tested in this section is guaranteed period in years $(N=2, N=3, N=4$ and $N=5)$ and the guaranteed amount $\left(K=S_{0}, K=0.9 S_{0}, K=0.8 S_{0}, K=0.7 S_{0}\right.$ and $\left.K=0.6 S_{0}\right)$. Note that we also the base case used in the previous sub-section.

Table 4 shelves all the statistical value tested on the $K$ variations including risk and return improvement of joining FRG program based on Equations (5)-(7).

From the Table 4, we can observe that as the value $K$ lower, the impact of guaranteeis not existing. Only $K=1$ and $K=0.9$ gives impact to the values, while $K=0.8$ barely changes from non-FRG case and $K=0.7$ and $K=0.6$ completely similar to non-FRG case. Even though this also occurred because our base setting, but we can observed that higher $K$ gives more impact to the values as return is increasing while the risk is decreasing. This fact is intuitive given that higher $K$ will also increase the probability that the revenue willfall below the $K$ level at time $N$, which mean forcing the franchisor to pay the revenue shortfall as agreed in FRG contract.We also can see the improvement only significant at $K=1$ and flatter as $K$ lower. In the next chapter we also going to discuss more on how $K$ impacted the FRG fee.

The second part of this sub-section we are going to observe the impact of $P V$ from $F R G$ period. The variables that have been tested are $N=2, N=3, N=4$ and $N=5$ in which $N$ represent years of guaranteed period. Table 5 shelves all the statistical value on the $N$ variations tested including risk and return improvement of joining $F R G$ program based on Equations (5)-(7).

As seen above, adding the period of guaranteed obviously adding value to $P V$ values as RRimp increasing substantially. Even though this result is highly intuitive, choosing longer period doesn't mean higher value for the franchisee as we have not consider the FRG fee yet. In the next section we will focus on this issue.

\section{FRG Fee (Put Premium)}

In the previous section we already compared the franchisee's $P V$ in joining or not joining the FRG program. However, we have not consider that there will be a fee occurring if franchisee decided to join FRG program. The fundamental idea of FRG agreement is the franchisor has to pay the revenue shortfall if during the guaranteed period the revenue fall below the amount agreed at the time franchisor and franchisee sign the contract. On the other hand, if realized revenue is more than that amount, franchisor oblige nothing and franchisee can take away all the revenue. 


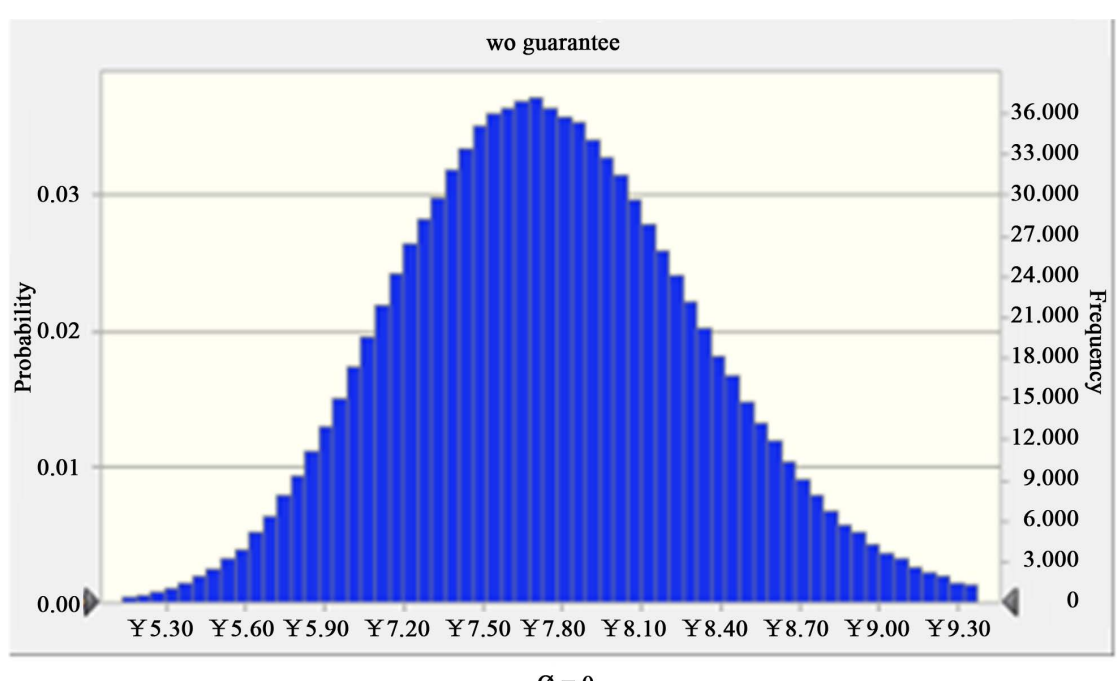

(a)

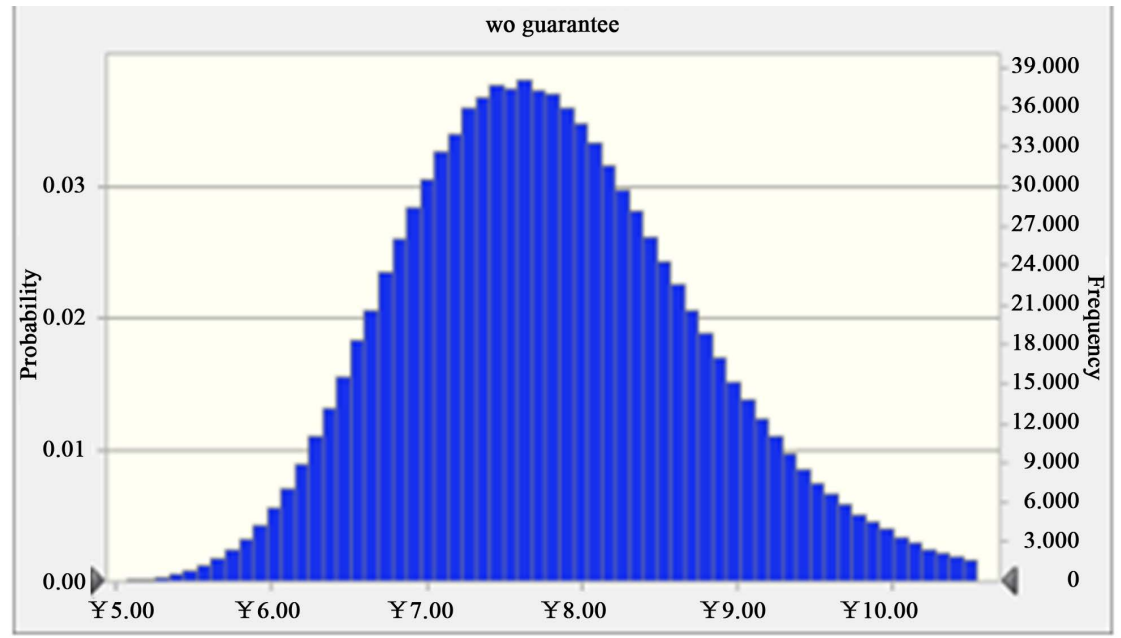

(b)

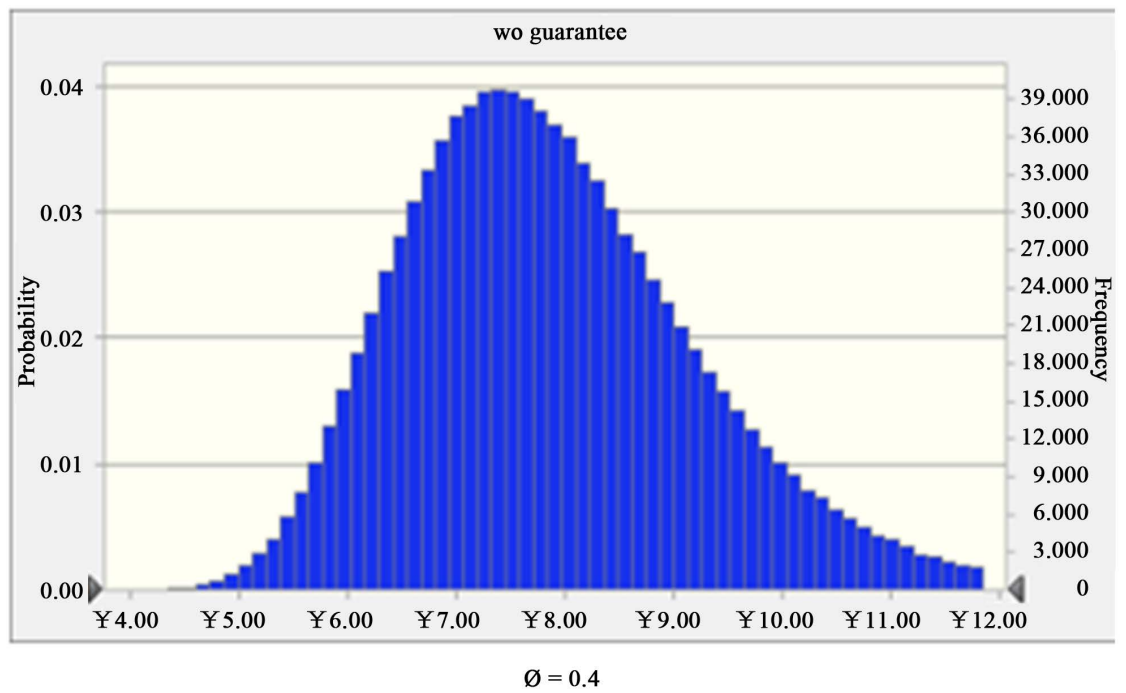

(c) 


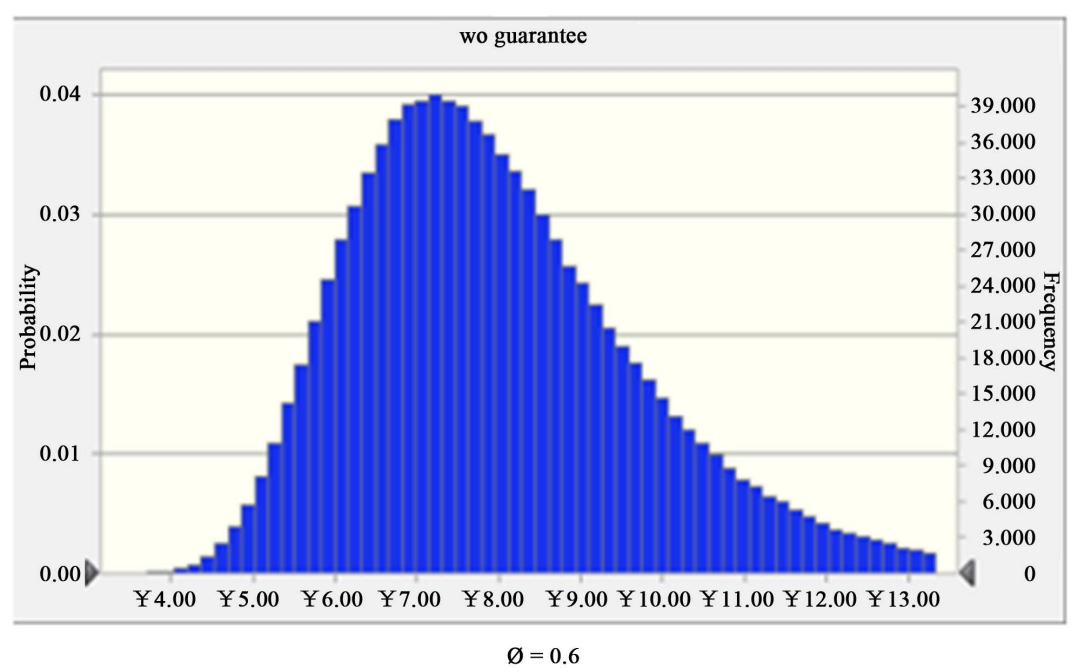

(d)

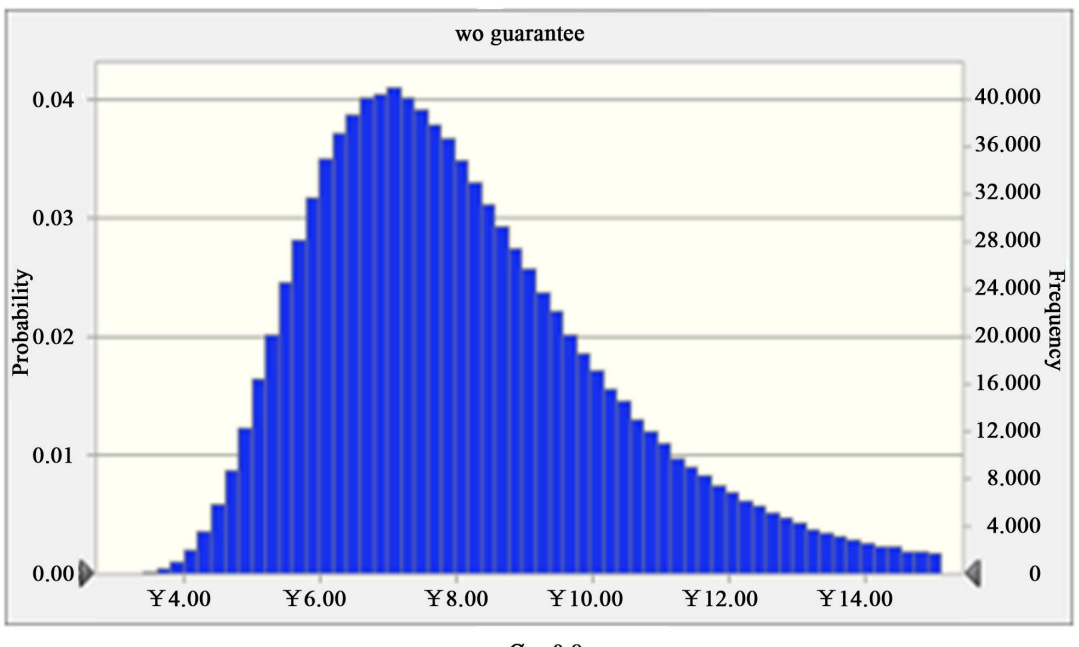

(e)

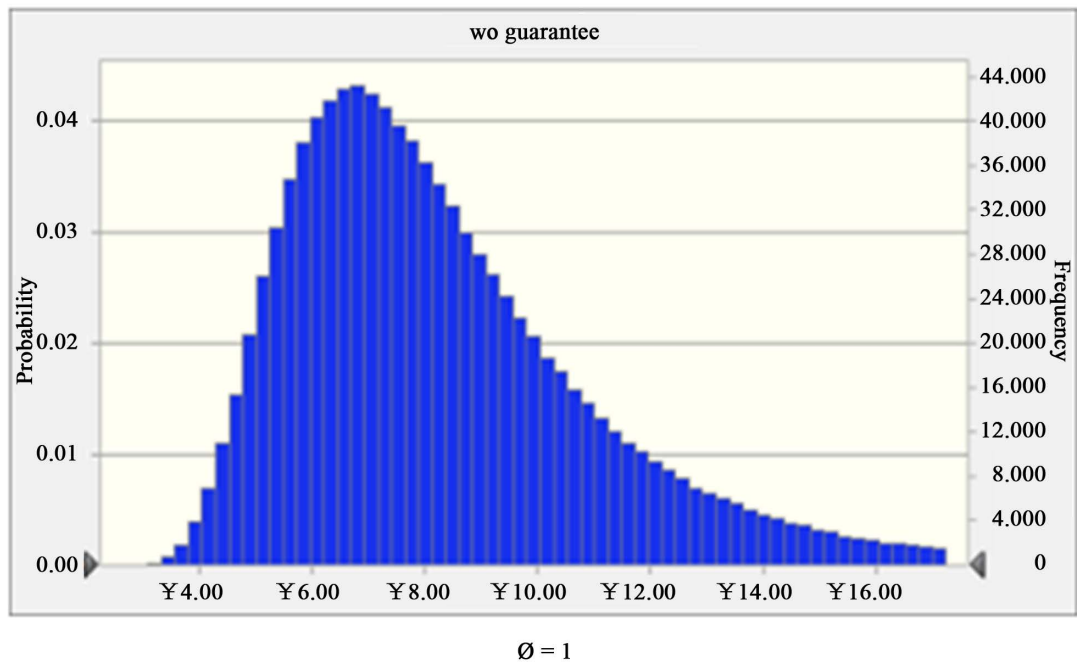

(f)

Figure 3. Illustration of $P V$ values on $\varnothing$ variations. 


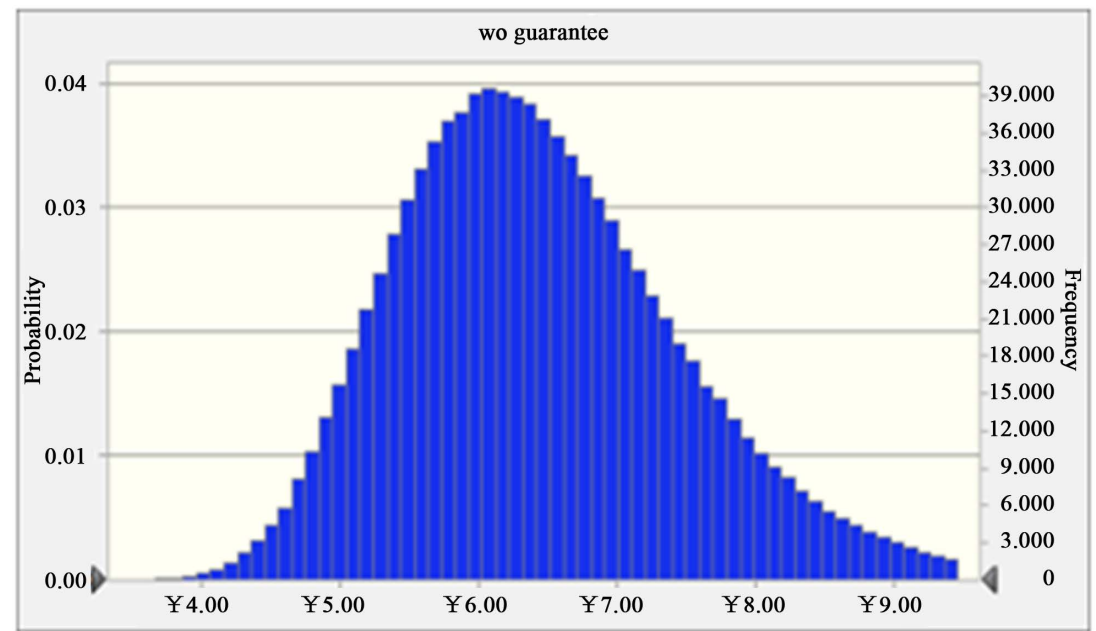

$\mu_{0}=-4 \%$

(a)

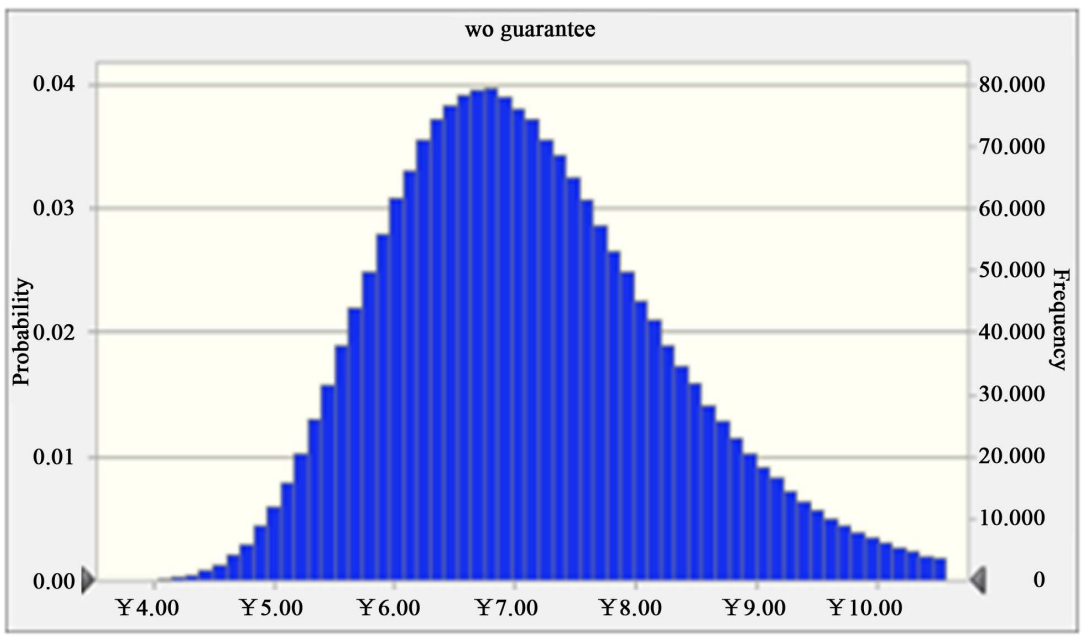

$\mu_{0}=-2 \%$

(b)

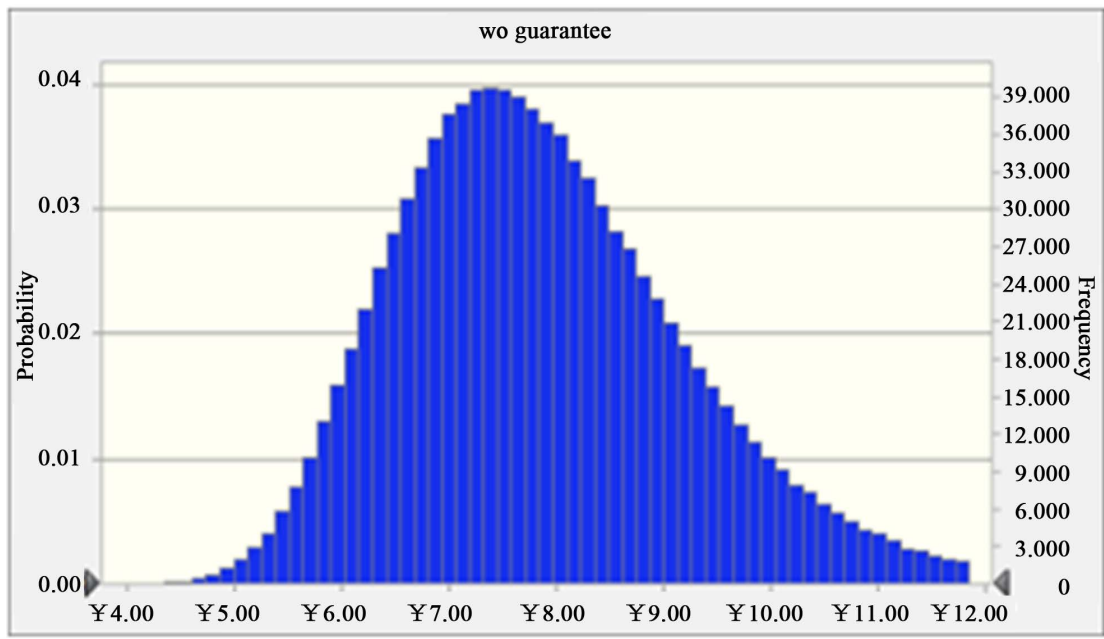

$\mu_{0}=0 \%$

(c) 


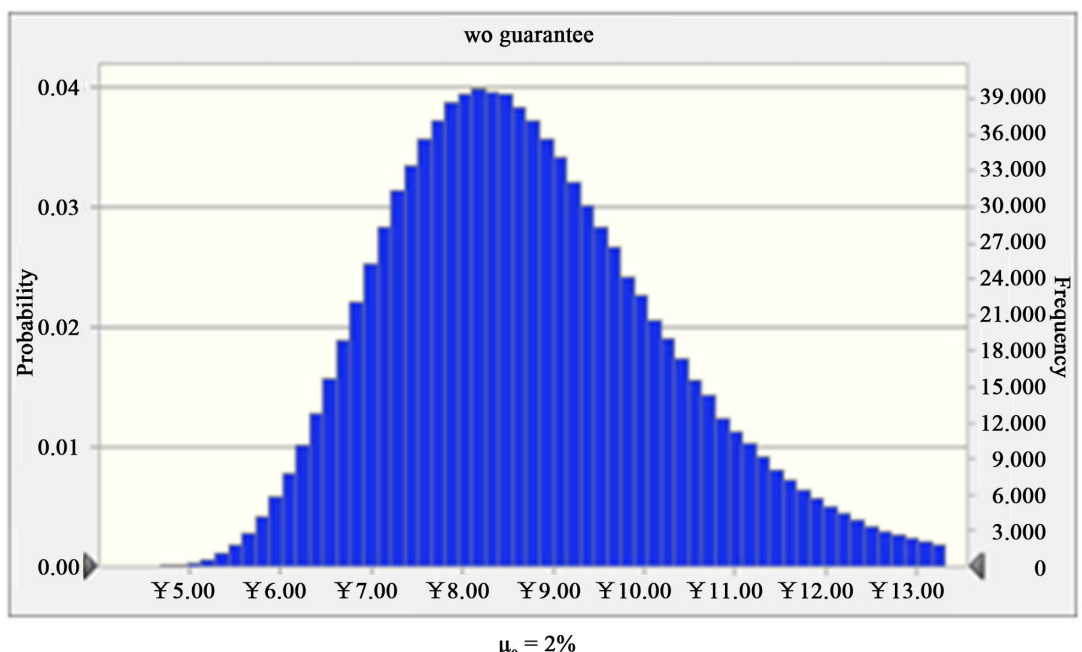

(d)

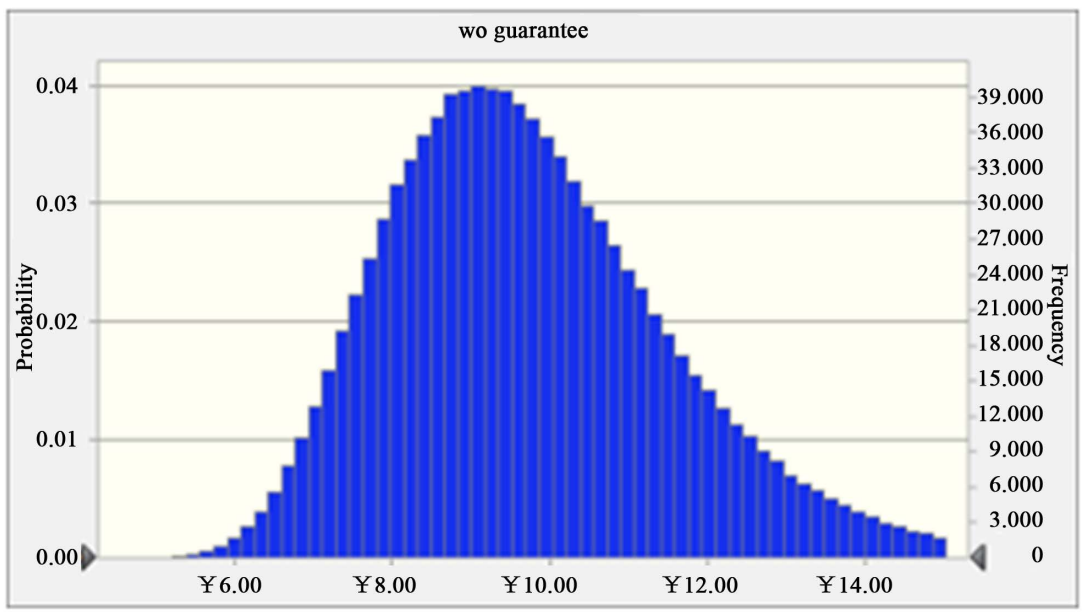

(e)

Figure 4. Illustration of $P V$ values on $\mu_{0}$ variations.

Table 3. $P V$ values on $\mu_{0}$ variation.

\begin{tabular}{|c|c|c|c|c|c|}
\hline \multirow{2}{*}{$\mu_{0}$} & \multicolumn{5}{|c|}{ Statistics } \\
\hline & Mean & $L S D$ & Skewness & Kurtosis & Range width \\
\hline$-4 \%$ & 6.467 & 0.682 & 0.739 & 4.056 & 13.396 \\
\hline$-2 \%$ & 7.136 & 0.780 & 0.752 & 4.064 & 14.528 \\
\hline 0 & 7.899 & 0.893 & 0.779 & 4.149 & 15.212 \\
\hline $2 \%$ & 8.733 & 1.026 & 0.792 & 4.188 & 19.996 \\
\hline $4 \%$ & 9.777 & 1.183 & 0.802 & 4.197 & 25.223 \\
\hline
\end{tabular}

Table 4. $P V$ values on $K$ variation.

\begin{tabular}{|c|c|c|c|c|c|c|c|c|}
\hline \multirow{2}{*}{ K } & \multicolumn{8}{|c|}{ Statistics } \\
\hline & Mean & $L S D$ & Skewness & Kurtosis & Range width & rMEAN & $r L S D$ & RRimp \\
\hline NonFRG & 7.899 & 0.893 & 0.779 & 4.419 & 15.212 & 0 & 0 & 0 \\
\hline $1 S_{0}$ & 7.970 & 0.834 & 0.913 & 4.436 & 14.586 & $0.90 \%$ & $6.5 \%$ & $70.7 \%$ \\
\hline $0.9 S_{0}$ & 7.906 & 0.881 & 0.814 & 4.180 & 14.858 & $0.09 \%$ & $1.29 \%$ & $12.36 \%$ \\
\hline $0.8 S_{0}$ & 7.899 & 0.892 & 0.782 & 4.419 & 15.040 & 0 & $0.08 \%$ & $0.74 \%$ \\
\hline $0.7 S_{0}$ & 7.899 & 0.893 & 0.779 & 4.419 & 15.167 & 0 & 0 & 0 \\
\hline $0.6 S_{0}$ & 7.899 & 0.893 & 0.779 & 4.419 & 15.212 & 0 & 0 & 0 \\
\hline
\end{tabular}


Table 5. $P V$ values on $N$ variation.

\begin{tabular}{|c|c|c|c|c|c|c|c|c|}
\hline \multirow{2}{*}{$\mathrm{N}$} & \multicolumn{7}{|c|}{ Statistics } & \multirow[b]{2}{*}{ RRimp } \\
\hline & Mean & $L S D$ & Skewness & Kurtosis & Range width & rMEAN & $r L S D$ & \\
\hline NonFRG & 7.899 & 0.893 & 0.779 & 4.419 & 15.212 & 0 & 0 & 0 \\
\hline 2 & 7.936 & 0.865 & 0.838 & 4.310 & 18.639 & $0.48 \%$ & $3.04 \%$ & $32.08 \%$ \\
\hline 3 & 7.970 & 0.834 & 0.913 & 4.436 & 14.586 & $0.9 \%$ & $6.5 \%$ & $70.07 \%$ \\
\hline 4 & 8.011 & 0.797 & 1.015 & 4.692 & 18.047 & $1.42 \%$ & $10.75 \%$ & $120.65 \%$ \\
\hline 5 & 8.056 & 0.748 & 1.145 & 4.997 & 16.149 & $1.99 \%$ & $16.19 \%$ & $191.95 \%$ \\
\hline
\end{tabular}

However, since nobody knows the exact amount of future's revenue, it is difficult for franchisor to setup the $F R G$ fee. One possible method to valuate this problem if we address FRG agreement as real options, mimicking put options in financial options.

If franchisee decided to join FRG program, the franchisor's obligation to pay in year $N, P_{N}$, would depend on the relative value between guaranteed amount, $K$, and realized revenue at year $N, S_{N}$, as shown in Equation (8);

$$
P_{N}=\max \left(K-S_{N}, 0\right)
$$

In other words, the options valuation problem is to determine the correct and fair price of the option at the same time franchisee and franchisor sign the contract $\left(S_{0}\right)$. Simply discounting Equation (8) would not solve the problem because the stochastic nature of $S_{N}$ (Hull, 2010);

$$
P_{0}=\frac{1}{(1+d)^{N}} E^{*}\left[\max \left(K-S_{N}, 0\right)\right]
$$

One of the possible method is through Monte Carlo simulation which will give us observation the value of $E^{*}\left[\max \left(K-S_{N}, 0\right)\right]$ at the terminal time, $N$;

$$
\left\{S_{N}^{(i)}=S^{(i)}(N), i=1, \cdots, M\right\}
$$

Equation (10) produces one possible option value at expiration (time $N$ ) and after computation this equation $M$ times in order to obtain a feel for the possible error in estimating the price.

After simulating $M$ times, FRG fee can be calculated by Equation (11) below;

$$
P_{0}=\frac{1}{(1+d)^{N}}\left[\frac{1}{M} \sum_{i=1}^{M} \max \left(K-S_{N}^{(i)}, 0\right)\right]
$$

With $P_{0}$ is the FRG fee for $N$ years, discounted with discount rate $d$ which obtained by simulated $M$ iterations of $\max \left(K-S_{N}, 0\right)$.

Using Equation (11), franchisor can calculate how much they should charge for $F R G$ fee $\left(P_{0}\right)$, then franchisee will decide either to join FRG program or not based on this fee and their viewpoint of the franchise in the future. Details on this decision will be discussed in the next section.

\section{Should Franchisee Join FRG? Discussion and Implication}

In this section, we want to analyze the franchisee decision in joining the FRG program. We relaxed the assumption on FRG characteristic so that franchisee can decide for the amount of FRG $(K)$ and period of $F R G(N)$. It is formulated in the previous section that put premium or FRG fee is a function of six components;

$$
P_{0}=f\left(S_{\text {sor }}\left(\sigma, \varnothing, \mu_{0}\right), K, N, d_{\text {sor }}\right)
$$

where $S_{\text {sor }}$ is revenue stochastic process in the franchisor point of view which is a function of volatility ( $\sigma$ ), smoothing parameter $(\varnothing)$ and initial drift $\left(\mu_{0}\right)$. While $d_{\text {sor }}$ is discount rate used by franchisor.

On the other hand, $P V$ of franchisee is also have six components;

$$
P V=f\left(S_{\text {see }}\left(\sigma, \varnothing, \mu_{0}\right), K, N, d_{\text {see }}\right)
$$

where $S_{\text {see }}$ is revenue stochastic process in the franchisee point of view and $d_{\text {see }}$ is franchisee's discount rate.

Based on Equations (12) and (13); 
- The three variables $\left(\sigma, \varnothing, \mu_{0}\right)$ that defines the stochastic process are the one which both franchise and franchisor cannot control. While $K$ and $N$ are the characteristic of the FRG. The $d_{\text {sor }}$ and $d_{\text {see }}$ is discount rate applied to the both of equations which depend on viewpoints of both party.

- From all variables, only the guaranteed amount $(K)$ and period of guarantee $(N)$ explicitly disclosed before both party sign the contract, franchisee and franchisor could have different value regarding other variables.

- If we assumed that franchise and franchisor has similar outlook to the future of franchise, the franchisee would likely will join $F R G$ if $d_{\text {see }} \geq d_{\text {sor }}$. The value of discount rate is actually one of the form of opportunity cost concept, which is the return that would be required of an investment to make it a viable alternative to other similar investments (Bennigga \& Czaczkes, 2008). Thus the discount rate could form as another opportunity cost, for instance; the venture capitalist usually use discounted rate that adjusted to the risk inherent to the project, while WACC (Weighted Average Cost of Capital) mostly used in general valuation.

- If all variables equal, franchisee would get the fair FRG fee. This condition will perfectly mimicking put options premium in the stock market. So either options buyer (franchisee) or options seller (franchisor) are exposed with similar risk profile. This setup will origin of the economic function of derivatives itself; it enables the transfer of risk for a fee, from those who do not want to bear it (franchisee) to those who are willing to bear risk (franchisor).

\section{Conclusion}

In this paper, we constructed analytical framework of revenue guarantee in business format franchising. Differing from other papers, the revenue stochastic process is assumed to follows log-DD process. This stochastic process features are discrete time and path-dependent, this approach deemed more realistic for non-financial asset compare to continuous time and path-independent that offered by Brownian Motion. Moreover, the cost of joining revenue guarantee using real options also derived. This calculation is useful for franchisor in setting up the revenue guarantee fee.

The model then tested in simulation which reveal that revenue guarantee more needed if uncertainty is high, but the cost of joining program will be expensive. Franchisee decision in joining revenue guarantee program would depend on future projection of revenue and discount rate used by both party.

\section{Acknowledgements}

Author would like to thank you Professor Takeaki Kariya, Professor Koji Inui and Professor Masayasu Mimura for all their contributions in this paper. This work is jointly supported by the Meiji University Global Center of Excellence (GCOE) Program and MEXT scholarship (Monbukagakusho).

\section{References}

Bates, T. (1998). Survival Patterns among Newcomers to Franchising. Journal of Business Venturing, 13, 113-130. http://dx.doi.org/10.1016/S0883-9026(97)00066-9

Bennigga, S. A., \& Czaczkes, B. (2008). Financial Modelling (3rd ed.). Cambridge: MIT Press.

Blair, R. D., \& Lafontaine, F. (2005). The Economics of Franchising. Cambridge: Cambridge University Press. http://dx.doi.org/10.1017/CBO9780511753879

Chiara, N., Garvin, M. J., \& Vecer, J. (2007). Valuing Simple Multiple-Exercise Real Options in Infrastructure Projects. Journal of Infrastructure Systems, 13, 97-104. http://dx.doi.org/10.1061/(ASCE)1076-0342(2007)13:2(97)

Hull, J. (2010). Options, Futures, and Other Derivatives, 7/e (with CD). India: Pearson Education.

Jun, J. (2010). Appraisal of Combined Agreements in BOT Project Finance: Focused on Minimum Revenue Guarantee and Revenue Cap Agreements. International Journal of Strategic Property Management, 2, 139-155. http://dx.doi.org/10.3846/ijspm.2010.11

Kariya, T., \& Liu, R. Y. (2002). Asset Pricing Discrete Time Approach. Dordrecht: Kluwer Academic Publishers.

Kariya, T., Kato, Y., Uchiyama, T., \& Suwabe, T. (2005). Tenant Management and Lease Valuation for Retail Properties: A Real Options Approach. International Real Estate Review, 8, 44-82.

Lee, K. (2010). The Firm's Value of Franchising and Its Investment Timing and Royalties, a Real Options Approach. International Research Journal of Finance and Economics, 43, 128-138. 
Wibowo, A., \& Kochendoerfer, B. (2011). Selecting BOT/PPP Infrastructure Projects for Government Guarantee Portfolio under Conditions of Budget and Risk in the Indonesian Context. Journal of Construction Engineering and Management, 137, 512-522. http://dx.doi.org/10.1061/(ASCE)CO.1943-7862.0000312 